\title{
The BMRES 1984 Medical Research Expedition to the Himalayas
}

\author{
A.R. Bradwell and J.H. Coote \\ Immunodiagnostic Research Laboratory, Department of Immunology, Medical School, University of Birmingham, \\ Edgbaston, Birmingham B15 2TH, UK.
}

\begin{abstract}
Summary: Twenty-one subjects formed a trekking expedition to study the effects of acetazolamide on exercise performance and acclimatization at high altitude. Subjects were randomized to acetazolamide or placebo on a double blind basis. During ascent to and stay for 6 nights at $\mathbf{4 8 4 6} \mathrm{m}$ studies were carried out on blood gases, 2,3 diphosphoglycerate (2,3 DPG), proteinuria, exercise testing, intestinal absorption, purine metabolism and changes in body composition. The results showed beneficial effects of acetazolamide on exercise performance and preservation of muscle mass.
\end{abstract}

\section{Introduction}

The Birmingham Medical Research Expeditionary Society (BMRES) was formed in 1977 by a group of doctors and scientists at Birmingham University to investigate aspects of mountain medicine. ${ }^{1}$ Since then the Society have carried out four major expeditions culminating in the 1984 expedition to Nepal, the results of which are the subject of this symposium. The earlier investigations included the use of acetazolamide $^{2}$ and methazolamide ${ }^{3}$ for prophylaxis of acute mountain sickness and the assessment of proteinuria at high altitude. ${ }^{4}$ The results have encouraged the use of acetazolamide, particularly amongst trekkers, on the world's highest mountains and has probably increased the safety and enjoyment of mountain travel.

However, opinions on acetazolamide have not been entirely favourable and there has been little enthusiasm for its use amongst climbers. This is for several reasons. First, there have been no satisfactory studies of the drug in acclimatized subjects at high altitude. Whilst trekkers may benefit from its use when ascending rapidly, climbers tend to ascend more slowly in order to acclimatize, which might render the drug less appropriate. Second, it is not known whether acetazolamide adversely affects exercise at altitude. Since there is evidence that sea level exercise is reduced by acetazolamide 5 similar findings at high altitude would be of great concern. Other objections include side effects (although the drug does have an excellent safety record) and moral attitudes. The answer to these depends upon circumstances; the balance of advan-

Correspondence: A.R. Bradwell M.B., Ch.B., F.R.C.P., M.R.C. Path. tages and disadvantages and the mountain dangers involved.

The purpose of our recent expedition was to collect relevant data and thereby allow us to make a recommendation as to the value of acetazolamide for climbers. Our results were presented at this symposium.

\section{The Expedition}

The group comprised 19 men and 2 women (aged 22 to 56), twelve of whom were medically qualified. All normally resided at less than $200 \mathrm{~m}$ and none had been to high altitude in the previous 6 months. All were in good general health. After a flight to Katmandu in Nepal at $1300 \mathrm{~m}$ the group walked for 11 days from Gorka to Rupina La at 4846 m (see Figure 1). They stayed at this height for 6 days (eight subjects ascended to $5700 \mathrm{~m}$ during one day) and then descended rapidly to Katmandu. Ascent was gradual to minimize the symptoms of acute mountain sickness (AMS) and allow good acclimatization (Figure 2).

Subjects were randomized by an independent observer to acetazolamide or placebo groups using stratification by age or sex. All subjects took acetazolamide for $48 \mathrm{~h}$ before departure from the UK. At the time of departure the experimental treatment was started on a double blind basis. The dose of acetazolamide was $500 \mathrm{mg}$ in a sustained released capsule (Diamox Sustet) taken each morning. Compliance as judged by personal account was very good. Treatment was stopped on the last day at high altitude. The severity of AMS was determined using clinical 


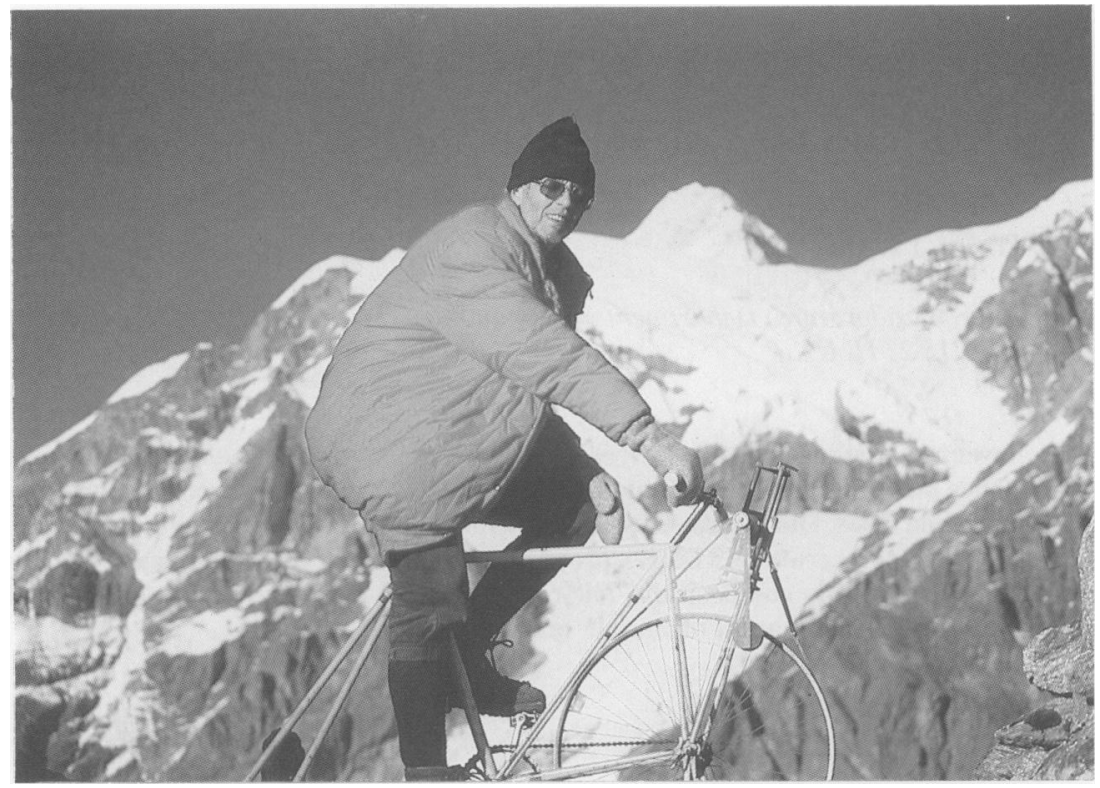

Figure 1 Prof John Coote on Pugh's exercise bicycle at Rupina La (5000 m)

assessment and peer review score. ${ }^{6}$ Two subjects descended prematurely from $4500 \mathrm{~m}$ (the ninth day); one was suffering from severe headaches which stopped after descending (presumably AMS); the second had bronchitis whilst a third person was well but assisted the others to the nearest town. Two of the three rejoined the group 3 days later at the top camp. Many subjects suffered from minor colds and coughs during the early and middle part of the expedition and many received antibiotics. Few subjects had gastrointestinal disturbances. This low incidence was possibly attributable to the use of iodine in all drinking water.

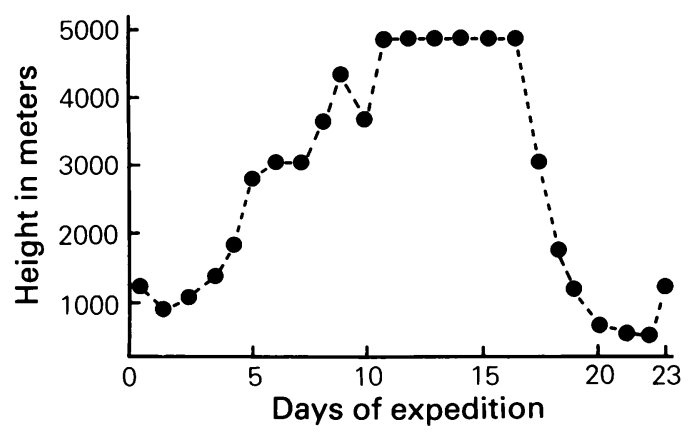

Figure 2 Route profile of BMRES 1984 expedition.
During the expedition numerous observations we made including changes in body composition ${ }^{7}$ and intestinal absorption, ${ }^{8}$ effect of acetazolamide on exercise performance ${ }^{9}$ and blood lactate responses, ${ }^{10}$ the origin of high altitude proteinuria, ${ }^{11}$ changes in breath holding times, ${ }^{12} 2,3$ DPG levels ${ }^{13}$ and purine metabolism $^{14}$ and the effect of sedatives on sleep. ${ }^{15}$

\section{Acknowledgements}

The study was generously supported by grants from many organisations including the following:

The Wellcome Trust, International Wool, Wyeth $\frac{7}{0}$ Laboratories, Eberspacher UK Ltd, The Arthur Thompson Trust, Canning Trust, West Midlands Regional Health $\mathcal{N}$ Authority, VA Howe Ltd, University of Birmingham, N Damart Thermawear Ltd, The Samuel Scott Trust, Duracell, ㅇ The Royal Society, Wesleyan \& General Assurance Society, $\omega$ The Physiological Society, Duncan Flockhart \& Co Ltd, Squibb Medical Supplies, Allen \& Hanbury's Ltd, Lederle 0

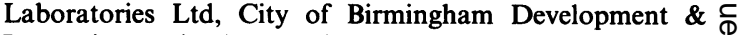
Promotion Unit, ACT Ltd, Lodge Cotterill Ltd, CP Ins- 只 truments.

The expeditionary arrangements in Nepal were organised through the Sherpa Co-operative by Mike Cheney. 


\section{References}

1. Symposium; Acute Mountain Sickness. Postgrad Med J 1979, 55: 445-512.

2. Birmingham Medical Research Expeditionary Society. Acetazolamide in the control of acute mountain sickness. Lancet 1981, i: $180-183$.

3. Wright, A.D., Bradwell, A.R. \& Fletcher, R.F. Methazolamide and acetazolamide in acute mountain sickness. Aviat Space Environ Med 1983, 54: 619-621.

4. Bradwell, A.R. \& Delamere, J.P. The effect of acetazolamide on the proteinuria of altitude. Aviat Space Environ Med 1982, 53: 40-43.

5. Heigenhauser, G.J.F., Sutton, J.R. \& Jones, N.L. Ventilation and carbon dioxide output during exercise: effects of glycogen depletion and carbonic anhydrase inhibition. Med Sci Sports 1980, 12: 123.

6. Fletcher, R.F., Wright, A.D., Jones, G.T. \& Bradwell, A.R. The clinical assessment of acute mountain sickness. $Q J$ Med 1985, 54: 91-100.

7. Dykes, P.W., Binns, N., Bradwell, A.R. et al. Changes in body weight, fat and muscle mass at high altitude and the effect of acetazolamide. Postgrad Med J 1987, 63: 191 (abstract)

8. Chesner, I.M., Small, N.A. \& Dykes, P.W. Intestinal absorption at high altitude. Postgrad Med J 1987, 63: 173-175.
9. Coote, J.H., Bradwell, A.R., Winterborn, M.H. \& Chesner, I. The effect of carbonic anhydrase inhibitors on exercise at high altitude. Postgrad Med J 1987, 63: 191 (abstract)

10. Binns, N., Wright, A.D., Singh, B.M., Coote, J.H. \& Bradwell, A.R. Blood lactate changes during exercise at high altitude. Postgrad Med J 1987, 63: 177-178.

11. Winterborn, M.H., Bradwell, A.R., Chesner, I.M. \& Jones, G.T. The origin of proteinuria at high altitudes. Postgrad Med J 1987, 63: 191 (abstract)

12. Morrissey, S.C., Keohane, K. \& Coote, J.H. The effect of acetazolamide on breath holding at high altitude. Postgrad Med J 1987, 63: 191 (abstract)

13. Milles, J.J., Chesner, I.M., Oldfield, S. \& Bradwell, A.R. Effect of acetazolamide on blood gases and 2,3 DPG during ascent and acclimatization to high altitude. Postgrad Med J 1987, 63: 191 (abstract).

14. Forster, P.J.G., Rylance, H.J., Wallace, R.C. \& Nuki, G. Changes in serum and urinary purines at high altitude. Postgrad Med J 1987 63: 191 (abstract).

15. Nicholson, A.N., Smith, P.A., Stone, B.M., Bradwell, A.R. \& Coote, J.H. Effects of acetazolamide and temazepam on sleep at high altitude. Postgrad Med J 1987, 63: 191 (abstract) 